\title{
Primer and Probe Designing to Detect SNP rs 4073 in Interleukin-8 Gene in Iraqi Patients with Bronchial Asthma
}

\author{
${ }^{1}$ Media F. Ali Jan*, ${ }^{2}$ Basima Q. Hassan Al-Saadi, ${ }^{1}$ Hiba M. Abdel-Hassan Al-Khafaji, ${ }^{3}$ Muhaned K. Aneed \\ Al-Saedi \\ ${ }^{1}$ Department of Applied Sciences, University of Technology, Iraq \\ ${ }^{2}$ Institute of Genetic Engineering and Biotechnology for post graduate studies, University of Baghdad, Iraq \\ ${ }^{3}$ Iraqi Hereditary Company, Iraq
}

\section{Article information}

Article history:

Received: May, 23, 2021

Accepted: June, 20, 2021

Available online: September, 18, 2021

Keywords:

Bronchial asthma,

IL-8,

rs 4073

*Corresponding Author:

Media Faeq Ali Jan

Media.faik1995@gmail.com

\begin{abstract}
Asthma is one of the most prevalent non-communicable illnesses, and it has a significant influence on the quality of life for many people. Asthma is now thought to be a multifaceted condition, with interactions between genetic susceptibility, host factors, and environmental exposures increasingly being blamed for its pathogenesis. In respiratory illness, interleukin- 8 plays a critical function due to promoting phagocytosis and inducing angiogenesis. Also, identification and finding out the effect of these SNPs and how it can be dangerously related or contribute to a Bronchial Asthma disease. However, the available methods for detecting interleukin-8 gene polymorphism are direct and quantitative using Poly Chain Reaction (RT-PCR) in real time. Whole blood was isolated from 100 patients with asthma and 50 healthy individuals. The results of polymorphism in single nucleotides showed an essential role in the development of asthma and that the presence of these SNPs has a role in increasing the susceptibility of individuals to asthma, as the variation in the TT genotype at the site followed by the AT genotype at the same site shows high-risk damage.
\end{abstract}

\section{Introduction}

This study was aimed to detect IL-8 gene polymorphisms in blood samples of bronchial asthma patients. Also, identification and finding out the effect of these SNP and how it can be dangerously related or contribute to a Bronchial Asthma disease. Bronchial asthma is a chronic inflammatory condition affecting the lungs' airways. Asthma is a disorder in which your airways constrict, swell, and create excessive mucus [1]. Asthma is one of the most prevalent non-communicable diseases, and it has a significant influence on many people's quality of life. It is characterized by reversible airflow restriction, changeable and recurrent symptoms, and easily triggered bronchospasms. Wheezing, coughing, chest tightness, and shortness of breath are common symptoms. These might happen a few times each day or a few times every week. Asthma manifestations may be more terrible around evening time or with action, contingent upon the individual [2]. A blend of hereditary and natural factors is viewed 
as the reason for asthma. Air contamination and sensitivities are two ecological issues to consider. Drugs, for example, anti-inflammatory medicine and beta blockers are additionally potential causes [3-5]. Respiratory infections effect on lungs, nose, sinuses, and throat, especially when you have asthma. Respiratory infections are the main asthma trigger and can cause severe symptoms (an asthma episode or attack) [6].

The lung function tests like a pattern of symptoms and responsiveness to treatment over time are commonly used to make a diagnosis [7]. Around 300 million globally have asthma, with an additional 100 million expected by 2025 [8]. The identification of milder asthma episodes may have affected the rise in asthma prevalence. Because asthma is not a curable condition, the ultimate objective of asthma treatment is to alleviate symptoms, slow the course of the condition, and improve the overall quality of life [9].

There is some evidence to date that those with asthma are overrepresented among the adult patients who have been admitted to hospital with coronavirus disease 2019 (COVID-19). This overrepresentation may occur because severe acute respiratory syndrome coronavirus 2 (SARS-CoV-2) triggers asthma exacerbations, as other viruses do, which is why asthma is listed as a risk factor for COVID-19 morbidity [10].

Interleukin 8 (IL8 or chemokine (C-X-C motif) ligand 8, CXCL8) is a chemokine produced by macrophages and other cell types such as epithelial cells, airway smooth muscle cells and endothelial cells. Endothelial cells store IL-8 in the Weibel-Palade bodies, which are storage vesicles [11]. In humans, the interleukin-8 protein is encoded by the CXCL8 gene [12].

As an important upregulated cytokine for airway inflammation, IL-8 is mainly secreted during asthma in acute attack and during an inflammatory reaction in clinical remission [13]. IL-8 plays an important role in respiratory disease and is a known regulator of pulmonary inflammation and immunity [14]. With chemotaxis and activation effects on neutrophils, IL-8 leads to neutrophil accumulation in the airways of patients with BA. $[15,16]$.

Many studies focused on the role of the IL-8 gene in association with asthma. [17] Common genetic SNPs in asthma-related genes play a significant role in disease progression. Promoter region SNP IL-8 rs4073 A/T (-251A/T) has been connected to the regulation of transcriptional activity of the IL- 8 gene and the levels of IL-8 production [18-20].

\section{Materials and Methods}

This study took place during the period from October 2020 to May 2021. All the study experiments were performed at the University of Technology and Iraqi Hereditary company (IHC).

\subsection{Study Groups}

The time of sample collecting was from October/2020 to January/2021. The total number of participants in the study was 150 individuals, study groups included the following: -

Group 1: one hundred samples of Iraqi men and women diagnosed with asthma, aged between (20-61) years old. Samples were collected at the Specialist Centre for Allergy (Al-Russafa, Baghdad, Iraq), their clinical information was obtained from their hospital files and case-sheet records.

Group 2: Fifty samples of apparently healthy individuals of both sexes, aged between (24-64 years) were obtained for control.

\subsection{Blood Sampling}

For each participant, $3 \mathrm{ml}$ of whole blood was needed to be collected from the blood venous directly into an EDTAcontaining tube. This procedure was done under aseptic conditions. The blood samples were stored at $-20^{\circ} \mathrm{C}$. 


\subsection{DNA Extraction}

The DNA was extracted and purified from human whole blood samples using the EasyPure® Blood Genomic DNA Kit (Cat. No.: EE121). Then, gel electrophoresis (agarose 1\% and 1X TBE) [21] was used to confirm the presence of extracted DNA after the process of extraction as shown in (Fig. 1). For one hour, 70 volts of electricity were switched on. The DNA bands transition from the cathode (-ve) to the anode (+ve) poles. The Ethidium bromide-stained bands in the gel were shot using a UV transilluminator set under $365 \mathrm{~nm}$ [22]. The purity and concentration of the extracted DNA were done by The Quanta's ${ }^{\mathrm{TM}}$ Fluorometer which showed that the purity was ranged between (1.6-1.8) and the concentration of the extracted DNA ranged between $(60-80 \mathrm{mg} / \mu \mathrm{l})$.

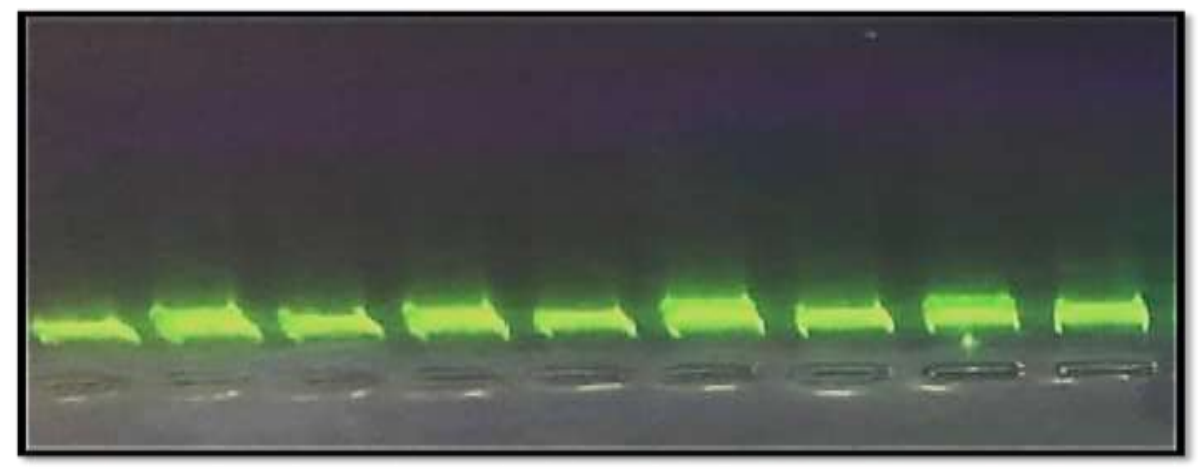

Figure 1: Gel-electrophoresis of DNA extracted from the whole blood sample.

\subsection{Primers and Probes}

Primers and Probes used in this study with their sequences are shown in (Table 1).

Table 1: Primers and Probes.

\begin{tabular}{|c|c|}
\hline Primer/probe & Sequence $\left(5^{\prime} \rightarrow 3^{\prime}\right.$ direction $)$ \\
\hline \multicolumn{2}{|c|}{ IL-8 gene SNP rs4073 } \\
\hline Forward & GTCACATGGTACTATGATAA \\
\hline Reverse & GAGTCATCACACTTCCTA \\
\hline FAM- probe & AAGCATACAATTGATAATTCACC \\
\hline VIC-probe & AAGCATACATTTGATAATTCACC \\
\hline
\end{tabular}

\subsection{Real Time PCR (qRT-PCR) for Genotyping Analysis}

QRT-PCR was performed using the Strata gene Real-time PCR System (Analytik Jena Technologies) with qPCRsoft software. Gene polymorphism was quantified by probe color reaction employing the 2xqPCR Master Mix Kits [23,24] components as shown in (Table 2). Each reaction was performed twice and included negative controls such as a non-template control (NTC), non-amplification control (NAC), and non-primer control (NPC).

Table 2: Reaction Component and volume for RT PCR used in IL-8 gene SNP experiment.

\begin{tabular}{|c|c|}
\hline Component & Volume \\
\hline Master mix 2x TransStart ${ }^{\circledR}$ Probe qPCR SuperMix & $12.5 \mu \mathrm{l}$ \\
\hline Forward primer & $2 \mu 1$ \\
\hline Revers primer & $2 \mu 1$ \\
\hline DNA & $4 \mu 1$ \\
\hline Nuclease free water (N.F.W) & $4.5 \mu 1$ \\
\hline
\end{tabular}




\subsection{The qPCR Reaction Run for Genotyping Analysis}

The cycling protocol was set up using the thermal profile as shown in (Table 3).

Table 3: Thermal profile used in allelic discrimination of IL-8 SNPs.

\begin{tabular}{|c|c|c|c|}
\hline Step & Temperature & Duration & Cycles \\
\hline Enzyme activation & $94^{\circ} \mathrm{C}$ & 30 Sec. & Hold \\
\hline Denature & $94^{\circ} \mathrm{C}$ & 5 Sec. & \multirow{2}{*}{$40-45$} \\
\hline Anneal & $54^{\circ} \mathrm{C}$ & 15 Sec. & \\
\hline Extend & $\mathbf{7 2}^{\circ} \mathrm{C}$ & $\mathbf{2 0 ~ S e c}^{\circ}$ & \\
\hline
\end{tabular}

\subsection{Genotyping/ Allelic Discrimination Principle}

The corresponding color (fluorophore) FAM, VIC at the 5' of the tests and a quencher tetramethyl rhodamine (TAMRA) at the 3' of the tests make up the TaqMan test. During the response, the cleavage of the test isolates the columnist color and the quencher color, bringing about fluorescence expansion of the journalist. The accumulation of these items is distinguished straight by checking the increment in fluorescence of the corresponding color. When the test is unblemished, the vicinity of the journalist color to the quencher color brings about concealment of the columnist fluorescence. During measure, if the objective of interest is available, the test explicitly strengthens to the objective. The 5' to 3' nucleolytic movement of the Taq DNA polymerase compound separates the test between the reporter and the quencher just if the test hybridizes to the objective.

The probe pieces are then moved from the target, and the strand continues to polymerize. The probe's third end was blocked, preventing it from being extended. Every cycle has this procedure, and it does not affect on the exponential buildup of product. Only if the target sequence is complementary to the probe can an increase in fluorescence signal be seen.

Alpha DNA Ltd (Canada) manufactured TaqMan fluorescent oligonucleotide probes and primer sequences for this investigation, which were lyophilized and kept at $\left(-23^{\circ} \mathrm{C}\right)$. Table 1 shows the sequences of the probes and primers used in the allelic separation contemplates, which contained the IL-8 gene SNP. Primer and probe sequence were matched by the bioinformatics programs NCLEAN BUFFERI and primer plus 3. The wild type detecting probe was labeled with FAM in the $5^{\prime}$ end and BHQ in the $3^{\prime}$ end. While the probe prepared for the mutant allele (SNP) was labeled with VIC in the $5^{\prime}$ end and BHQ in the $3^{\prime}$ end [25].

\section{Results and Discussion}

This study analyzed the distribution of the IL-8 gene polymorphism rs4073 in study groups and evaluated their association with asthma patients. The distribution of genotype and allele frequencies among patient groups compared with the healthy group for the IL-8 gene polymorphism rs4073 is shown in (Table 4). The genotype frequencies of asthma patients were $23.1 \%(n=29)$ normal AA and $23.1 \%(n=29)$ heterozygous AT. Mutant homozygous was found in TT 53.8\% $(n=42)$. In controls, the results show $64 \%(n=32)$ wild type AA, 16\% $(n=8)$ heterozygous AT and mutant homozygous TT 20\% (n=10).

The result of genotype frequencies of asthma patient's analysis shown in table 4 reveals that the wild type genotype and wild type allele were taken as reference. In IL-8 gene polymorphism rs4073, the odd ratio for the TT genotype was 4.6 with $p=0.0004$, indicating that homomutant genotype TT was at higher risk of asthma than wild type AA. The AT genotype have the second risk of asthma after TT with an odd ratio of 4 and $p=0.0035$. The frequency of the A allele in asthma patients and controls was 87 (22.5\%) and 72 (42.5\%), respectively. 
Table 4: Comparison of the Genotype and Allele Frequencies of IL8 gene poly morphism (rs4073) between patients' and the Healthy groups.

\begin{tabular}{|c|c|c|c|c|}
\hline \multirow{2}{*}{$\begin{array}{c}I L-8 \\
\text { polymorphism } \\
\text { rs } 4073\end{array}$} & \multicolumn{2}{|c|}{ Frequencies (\%) } & \multirow[b]{2}{*}{$P$ value } & \multirow[b]{2}{*}{$\begin{array}{l}\text { Odd ratio } \\
(95 \% \text { CI) }\end{array}$} \\
\hline & $\begin{array}{l}\text { Healthy } \\
(n=50)\end{array}$ & $\begin{array}{l}\text { Patients } \\
(n=100)\end{array}$ & & \\
\hline \multicolumn{5}{|l|}{$\begin{array}{c}\text { Co } \\
\text { dominant } \\
\end{array}$} \\
\hline $\mathbf{A A}$ & $64.0 \%(n=32)$ & $23.1 \%(n=29)$ & --- & 1.00 (Reference) \\
\hline AT & $16.0 \%(n=8)$ & $23.1 \%(n=29)$ & 0.0035 & $4(1.5-10.1)$ \\
\hline TT & $20.0 \%(n=10)$ & $53.8 \%(n=42)$ & 0.0004 & $4.6(1.9-10.8)$ \\
\hline \multicolumn{5}{|l|}{ Dominant } \\
\hline $\mathbf{A A}$ & $64.0 \%(n=32)$ & $23.1 \%(n=29)$ & --- & 1.00 (Reference) \\
\hline $\mathbf{A T}+\mathbf{T T}$ & $36.0 \%(n=18)$ & $76.9 \%(n=71)$ & 0.0001 & $4.3(2.1-8.9)$ \\
\hline \multicolumn{5}{|l|}{ Recessive } \\
\hline $\mathbf{A A}+\mathbf{A T}$ & $80.0 \%(n=40)$ & $46.2 \%(n=58)$ & --- & 1.00 (Reference) \\
\hline TT & $20.0 \%(n=10)$ & $53.8 \%(n=42)$ & 0.0091 & $2.8(1.3-6.4)$ \\
\hline \multicolumn{5}{|l|}{ Allele } \\
\hline $\mathbf{A}$ & $42.5 \%(n=72)$ & $22.5 \%(n=87)$ & --- & 1.00 (Reference) \\
\hline $\mathbf{T}$ & $57.5 \%(n=28)$ & $77.5 \%(n=113)$ & 0.0001 & $3.7(2.2-6.2)$ \\
\hline
\end{tabular}

Results of polymorphism in single nucleotides show an essential role in the development of asthma and that the presence of these SNPs has a role in increasing susceptibility of individuals to asthma, as the variation in the TT genotype at the site followed by the AT genotype at the same site shows high-risk damage as shown in (Fig. 2). 


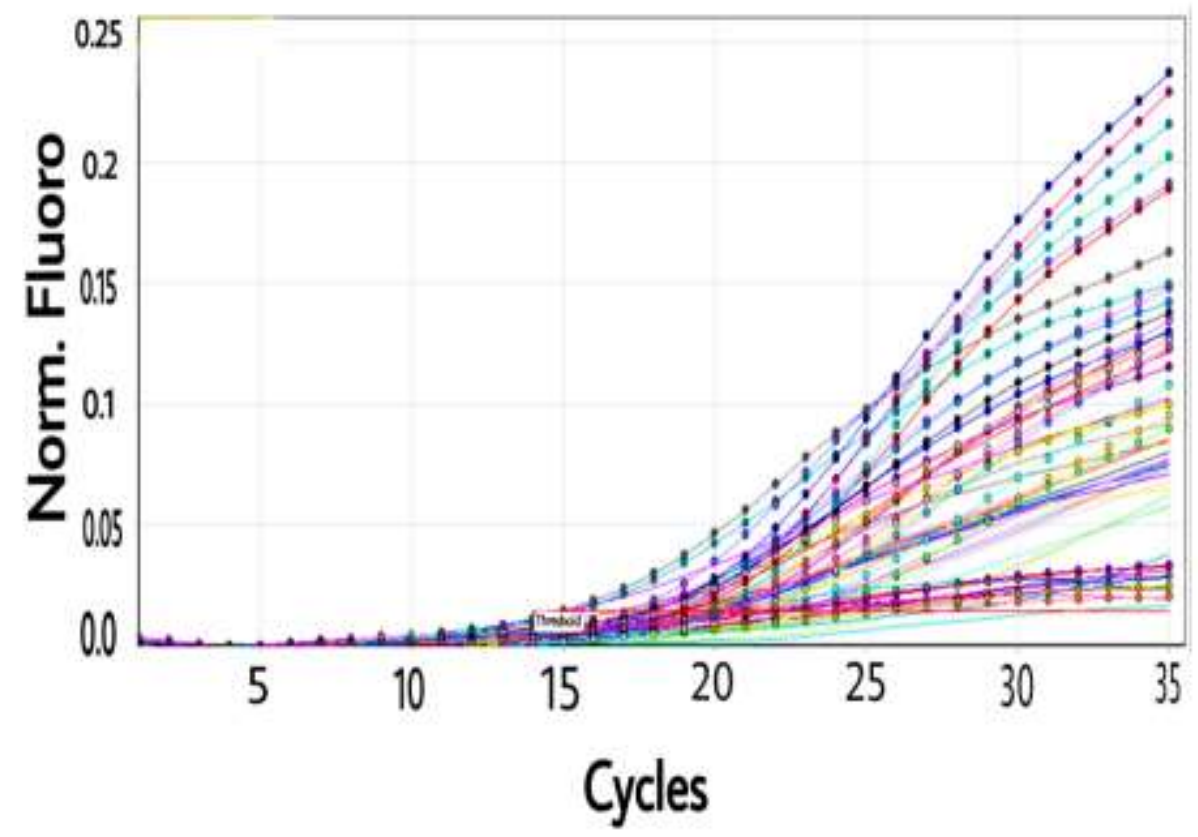

Figure 2: Allelic Discrimination Report generated by Rotor-Gene Q Series Software 2.1.0 (Cycling A. Green= No Markers, Cycling A. Yellow= Circles), show that sample with mutant genotype have a high reaction (samples color blue, black, red) followed by samples with heterozygous genotype (orange, green, pink) and samples with wild type genotype (purple, gray) have the lowest reaction.

\section{Conclusions}

SNP variations and different genotypes of IL-8 have significant parts in the improvement of asthma. Their application on such patients would segregate those with high powerlessness to DNA harm from low defenselessness. The TT and AT genotype were found to be associated with a higher risk of bronchial asthma.

\section{Acknowledgement}

We sincerely thank the faculty and staff members at both Institute of Applied Science Department / Biotechnology division / University of Technology and Iraqi Hereditary company (IHC).

\section{Conflict of Interest}

The authors declare that they have no conflict of interest.

\section{References}

[1] E. D. Bateman, S. S. Hurd, P. J. Barnes, et al., "Global strategy for asthma management and prevention: GINA executive summary," European Respiratory Journal, vol. 31, p. 143-178, 2008.

[2] M. C. Mirabelli, V. Ambarish, W. D. Flanders, et al., "Outdoor PM2.5, ambient air temperature, and asthma symptoms in the past 14 days among adults with active asthma," Environmental health perspectives, vol. 124, p.1882-1890, 2016.

[3] D. W. Cockcroft, "Environmental causes of asthma," Seminars in respiratory and critical care medicine, vol. 39, p. 012-018, 2018.

[4] D. R. Morales, J. L. Brian, T. D. Peter, et al., "Respiratory effect of beta-blockers in people with asthma and cardiovascular disease: population-based nested case control study," BMC medicine, vol. 15, p. 1-9, 2017.

[5] S. Isogai, N. Yoshikazu, Y. Hiroshi, et al., "Increased airway hyperresponsiveness to adenosine in patients with aspirin intolerant asthma," Allergology International, vol. 66, p. 360-362, 2017.

[6] N. Hussein and M. M. Khadum,"Evaluation of the Biosynthesized Silver Nanoparticles Effects on Biolfilm Formation," Journal of Applied Sciences and Nanotechnology, vol. 1, p.23-31, 2021. 
[7] A. Badnjević, G. Lejla, C. Mario, et al., "Classification of asthma using artificial neural network, In 2016 39th International Convention on Information and Communication Technology," Electronics and Microelectronics (MIPRO), p. 387-390, 2016.

[8] B., A. B. Mohamed, A. M., Abdulazzi, et al., "Asthma and its Associated Triggering Factors among Medical Students at Ha'il University," Saudi Journal of Pathology and Microbiology, vol. 3, p. 15, 2020.

[9] S. M. Rasmussen, H. H. Erik Sören, L. T. Louise, et al., "Diet and Exercise: A Novel Cure for Asthma -A Short Communications on a Non-Pharmacological Strategy.," Journal of Physical Medicine and Rehabilitation, vol. 2, 2020.

[10] B. A. Taha, "Perspectives of Photonics Technology to Diagnosis COVID-19 Viruses: A Short Review," Journal of Applied Sciences and Nanotechnology, vol. 1, p. 1-6, 2021.

[11] Q. He, S. Xiaojuan, Z. Bin, et al., "Interleukin 8 (CXCL8)-CXC chemokine receptor 2 (CXCR2) axis contributes to MiR-4437-associated recruitment of granulocytes and natural killer cells in ischemic stroke," Molecular immunology, vol. 101, p. 440-449, 2018.

[12] M. E. Meniailo, V. M. Vladimir, A. S. Vyacheslav, et al., "Interleukin-8 favors pro-inflammatory activity of human monocytes/macrophages," International immunopharmacology, vol. 56, p. 217-221, 2018.

[13] H. Bi, Z. Yu, W. Shanshan, et al., "Interleukin 8 promotes cell migration via CXCR1 and CXCR2 in liver cancer," Oncology letters, vol. 18, p. 4176-4184, 2019.

[14] M. Al-Kinani, A. Haider and S. Al-Musawi, "Study the Effect of Laser Wavelength on Polymeric Metallic Nanocarrier Synthesis for Curcumin Delivery in Prostate Cancer Therapy: In Vitro Study, "Journal of Applied Sciences and Nanotechnology, vol.1, p.43-50, 2021.

[15] Y., D.Xiao, J. R. Corvalan, et al., "Fully human anti interleukin-8 monoclonal antibodies: potential therapeutics for the treatment of inflammatory disease states," Journal of Leukocyte Biology, vol. 66, p. 401-410, 1999.

[16] A., A. Noha, L. Abd El Salam, et al., "Interferon gamma and interleukin 8 gene polymorphisms in patients with hepatitis C virus related oral lichen planus," Archives of oral biology, vol. 96, p. 189194, 2018.

[17] M. Xu, Y. Feng-Lai, W. Shu-Jing, et al., “Association of interleukin-18 and asthma,” Inflammation, vol. 40, p. 324-327, 2017.

[18] P. Gonzalez-Hormazabal, S. Romero, M. Musleh, et al., "IL-8-251T> A (rs4073) polymorphism is associated with prognosis in gastric cancer patients," Anticancer research, vol. 38, p. 5703-5708, 2018.

[19] Y. Li, J. Bai, B. He, et al., "Weak association between the interleukin-8 rs4073 polymorphism and acute pancreatitis: a cumulative meta-analysis," BMC medical genetics, vol. 20, p. 129, 2019.

[20] N. Kaur, J. Singh, and S. Reddy, "Association of IL-8-251 A/T rs4073 and IL-10 rs1800872-592C/A polymorphisms and coronary artery disease in North Indian population," Biochemical genetics, vol. 57, p. 129-146, 2019.

[21] M. R. Green, H. Hughes, J. Sambrook, et al., "Molecular cloning: a laboratory manual," In Molecular cloning: a laboratory manual, p. 1890-1890, 2012.

[22] M. R. Green and S. Joseph "Analysis of DNA by agarose gel electrophoresis," Cold Spring Harbor Protocols, vol. 2019, p. 100388, 2019.

[23] T. B. Yang, J. Liu, L. Y. Yuan, et al., "Molecular identification of spiders preying on Empoasca vitis in a tea plantation," Scientific reports, vol. 7, pp. 1-10, 2017.

[24] P. Wang, L. Huang, H. Jiang, et al., "Improving the secretion of a methyl parathion hydrolase in Pichia pastoris by modifying its N-terminal sequence," PloS one, vol. 9, p. 96974, 2014.

[25] Y. Liu, C. Yang, W. Tao, et al., "Detection of 12 common food-borne bacterial pathogens by TaqMan realtime PCR using a single set of reaction conditions," Frontiers in microbiology, vol. 10, p. 222, 2019. 